\title{
ESTRATEGIAS COMUNICATIVAS DE LA PRENSA EN TWITTER. UNA COMPARATIVA ENTRE ESPAÑA Y PORTUGAL
}

\section{Press Communication Strategies in Twitter. A Comparison between Spain and Portugal}

Estratégias comunicativas da imprensa no twitter. Uma comparativa entre a Espanha e o Portugal

PUEBLA MARTíNEZ, Belén. Universidad Complutense de Madrid (España)

bpuebla@ucm.es

GOMES-FRANCO E SILVA, Flávia. Universidad Rey Juan Carlos (España)

flavia.gomes@urjc.es

Fecha de recibido: 1 de septiembre de 2014

Fecha de aceptado: 13 de octubre de 2014

\section{RESUMEN}

El desarrollo de la web 2.0 ha ocasionado la aparición de diversos medios sociales, cuya dinámica da lugar al intercambio continuo de contenidos por parte de los usuarios. La consolidación del actual modelo comunicativo, caracterizado por la horizontalidad, la bidireccionalidad y la descentralización, constituye uno de los efectos más destacados de la interactividad en el proceso de construcción del escenario informativo. Con ello, los medios de comunicación tradicionales deben afrontar los desafíos que implican la adaptación del periodismo tradicional a la participación de la audiencia en la producción de contenidos y las nuevas formas de divulgación. El presente estudio propone un análisis de las estrategias comunicativas utilizadas por los cibermedios en el microblogging 
Twitter, haciendo hincapié en la adecuación del mensaje periodístico a la narrativa propia de este entorno digital. Con el objetivo de realizar una comparativa entre España y Portugal, se han analizado los perfiles de los diarios con mayor tirada en sus países de origen: El País (España) y Jornal de Notícias (Portugal). El estudio revela tanto la infrautilización del potencial conversacional de Twitter por parte de ambos periódicos como la necesidad inminente de establecer normas de estilo acerca del uso de recursos tales como las menciones o los hashtags.

Palabras clave: Cibermedios; ciberperiodismo, TIC, medios sociales, redes sociales, microblogging, Twitter, interactividad, España, Portugal.

\section{ABSTRACT}

The development of the Web 2.0 has caused the appearance of several Social Media, whose dynamics leads to a continuous exchange of content by users. The consolidation of the current communication model, characterized by the horizontality, bidirectionality, and decentralization, is one of the most prominent effects of the interactivity in the process of building the information scene. Thereby, traditional media must face the challenges involved in adapting the traditional journalism to the audience participation in content production and new ways of broadcasting. This study proposes an analysis of the communication strategies used by cybermedia on Twitter microblogging, emphasizing the adequacy of journalistic messages to the typical narrative of this digital environment. In order to make a comparison between Spain and Portugal, we have analyzed the profiles of the newspapers with the largest circulation in their countries of origin: El País (Spain) and Jornal de Notícias (Portugal). The study reveals both the underutilization of Twitter's conversational potential by both newspapers and the imminent need to set out style rules about the use of resources such as mentions or hashtags.

Keywords: Cybermedia, cyberjournalism, CIT, social media, social networks, microblogging, Twitter, interactivity, Spain, Portugal.

\section{RESUMO}

O desenvolvimento da web 2.0 tem ocasionado a aparição de diversos meios sociais, cuja dinâmica ocasiona o intercâmbio contínuo de conteúdos por parte dos usuários. A consolidação do atual modelo comunicativo, caraterizado pela horizontalidade, a bidirecionalidade e a descentralização, constitui um dos efeitos mais destacados da interatividade no processo de construção do cenário informativo. Com isto, os meios de comunicação tradicionais devem afrontar os desafios que implicam a adaptação do jornalismo tradicional à participação da audiência na produção de conteúdos e as novas formas de divulgação. O presente estudo propõe uma análise das estratégias comunicativas utilizadas pelos cibermeios no microblogging Twitter, batendo pé firme na adequação da mensagem jornalística à narrativa própria deste entorno digital. Com o objetivo de realizar uma comparativa entre a Espanha e o Portugal, se tem analisado os perfis dos jornais com maior tiragem em seus países de origem: El País (Espanha) e Jornal de Notícias (Portugal). O estudo revela tanto a subutilização do potencial conversacional do 
Twitter por parte de ambos os jornais quanto a necessidade iminente de estabelecer normas de estilo acerca do uso de recursos tais como as menciones ou os hashtags.

Palavras-chave: Cibermeios, ciberjornalismo, TIC, meios sociais; redes sociais, microblogging, Twitter, interatividade, Espanha, Portugal.

\section{Introducción}

El proceso evolutivo de la Red a partir de la incorporación masiva de elementos relativos a la interacción con los usuarios constituye uno de los principales aspectos que están modificando la manera tradicional de hacer periodismo. La web 2.0, que poco a poco va evolucionando hacia la semántica, simboliza el rescate de la filosofía del intercambio que estuvo presente en los planteamientos iniciales de Internet como una red de ordenadores conectados.

Más que un número que representa una versión novedosa de un artefacto, la web 2.0 es, por tanto, una filosofía que rige la lógica de la comunicación que se lleva a cabo vía Internet. Desde principios del siglo XXI, se han visto implementadas nuevas maneras de acceder a la información e incluso de elaborarla y divulgarla. Esta dinámica puede ser representada según la teoría de los networks de comunicación, cuya estructura actual promueve un desplazamiento de la inteligencia desde un nodo central hacia la periferia mediante el modelo end-to-end. Con ello, la información ya no fluye de uno a muchos (one-to-many), conforme a los medios puramente tradicionales, sino de muchos a muchos (many-to-many) (Font, 2003).

En esta línea, Baviera Puig (2002, p. 54) afirma que los principios de la conexión global se configuran en la descentralización, la flexibilidad y el intercambio abierto de información en "una cultura basada en la participación y en la colaboración desinteresada de los usuarios”. Dichas propiedades dibujan un escenario propicio a la creación de la sociedad red (Castells, 2008) a la vez que trastocan la forma habitual de acceso a los medios. "Internet se usa cada vez más para acceder a medios de comunicación (televisión, radio, periódicos), así como a cualquier forma de producto informativo o cultural digitalizado (película, música, revistas, libros, artículos de periódicos, bases de datos)" (Castells, 2009, p. 100).

La actividad continuada de los internautas en la Red ha dado lugar a la aparición de diversas herramientas 2.0 empleadas por ellos las 24 horas del día para consumir, compartir y producir contenidos. A partir del momento en el que las audiencias se transforman en usuarios proactivos de los llamados social media, los medios de comunicación asumen el desafío de garantizar su presencia en distintas plataformas y dispositivos con el fin de alcanzar a su público objetivo donde quiera que este se encuentre en el ámbito online.

En la presente investigación se retoman los retos de los medios en el proceso de adaptación a las Tecnologías de la Información y la Comunicación (TIC) para contextualizar el uso periodístico de las redes y medios sociales. Se observan las estrategias comunicativas empleadas por la prensa, en este caso, tanto en España como en Portugal, 
y el empleo de tácticas que establezcan un vínculo posible entre la objetividad de la información profesional y la narrativa propia de las plataformas interactivas.

\section{De los medios tradicionales a los cibermedios}

El creciente interés de los medios por garantizar un espacio en la Red a través de la creación de una página web ha impulsado el proceso migratorio de contenidos informativos de los soportes tradicionales a los digitales. García Galindo (2009) señala que la digitalización ha resultado ser "el mayor desarrollo tecnológico de la prensa durante estos últimos años". Respecto a la primera etapa de dicho proceso, Cabrera González (2010, p. 9) explica que:

Los medios tradicionales (primero la prensa, y después la televisión y la radio) han ido ofreciendo versiones y contenidos digitales, tanto off-line como online, que han terminado concibiéndose como el mismo medio de información pero en versión digital, como un servicio de información complementario al medio tradicional y, en los menos de los casos, como un medio o cibermedio totalmente diferente al original.

Si por un lado autores como Pisani (2002) critican la transferencia pasiva e inadecuada del periodismo tradicional a la web -cuya mera reproducción en la pantalla de los contenidos diseñados para otros soportes condenaría al fracaso al incipiente periodismo digital-, por otro lado, estudiosos como Rojo Villada (2010) inciden en la apertura de nuevos horizontes a la profesión. En ambos casos, queda patente la profunda reconfiguración de las tareas periodísticas, informativas y mediáticas provocadas por el advenimiento de Internet y la incorporación del prefijo "ciber-" a los medios de comunicación.

Una vez superada la fase inicial de reconocimiento y conquista de los espacios online, se normaliza la utilización del término "cibermedio", al que Alonso (2010, p. 27) conceptúa como "todos aquellos sitios web que poseen como función prioritaria la producción y/o gestión de contenidos de información periodística, en cualquiera de sus formas y modalidades". El autor promueve, con ello, una relectura de la definición elaborada años antes por Salaverría (2005, p. 13), quien se refiere a los cibermedios como "aquellos medios de comunicación social que emplean el ciberespacio como ámbito para la difusión pública de informaciones periodísticas”.

Sin embargo, ejercer en la práctica el mencionado concepto sigue representando un gran reto para las empresas de comunicación. En el caso de la prensa, por ejemplo, no se trata simplemente de reubicar el periódico tradicional en una nueva plataforma, sino adaptarlo a las posibilidades que esta le ofrece para ampliar sus servicios y hacerlos más atractivos a los usuarios. Una dificultad añadida es sin duda el gran abanico de herramientas por las que el público se dispersa, dando lugar a la fragmentación y a la dilución de la mediación (Campos Freire, 2008).

La web 2.0 ha sumergido el periodismo en un entorno repleto de plataformas digitales interactivas en las que los usuarios cobran protagonismo y dictan sus preferencias a la hora de elegir los contenidos que más les interesan. En esta coyuntura, cuyas características marcan el traslado "de una comunicación de masas a una comunicación más segmentada" (Alonso y Martínez, 2003, p. 271) y a la autocomunicación de masas (Castells, 2009), los cibermedios deben lidiar con las nuevas prioridades del público, atendiendo a la demanda de un contenido menos genérico (para la masa) y más especializado (para el usuario). 


\section{El ciberperiodismo en la era de los medios sociales}

Los medios sociales - "plataformas digitales de comunicación que dan el poder al usuario para generar contenidos y compartir información a través de perfiles privados o públicos" (IAB Spain, 2009, p. 6) - han modificado la relación entre el público y el periodismo. Si bien "el periodismo en red rompe con la jerarquización de los controladores de los medios e inicia otras formas de informar e informarse" (Flores, 2013: 16), los internautas asumen un papel cada vez más colaborativo en la construcción del actual ciberperiodismo.

En las plataformas sociales cohabitan una gran variedad de fuentes de información, sean oficiales, fiables o amateur. Redes como Facebook o Twitter e incluso la blogosfera albergan contenidos elaborados por internautas de todo el mundo, superando "los conceptos clásicos de emisores y receptores en aras de un emisor-receptor vinculado y entrelazado con muchos otros prosumidores" (Cebrián, 2013, p. 31). En estas webs se observa el desarrollo del periodismo participativo y ciudadano, puesto que "los procesos de producción, difusión, recepción e intercambio se convierten en algo plenamente interactivo” (Cebrián, 2008, p. 359).

La interactividad, descrita por Mallabiabarrena Acerecho y Meso Ayerdi (2011) como la principal aportación de los social media a los cibermedios, ha facilitado el acceso del público a la información desde distintas herramientas 2.0, ofreciendo, asimismo, diversos espacios destinados a la participación de la audiencia. En el proceso de adaptación a la dinámica de las redes, el periodismo va sustituyendo paulatinamente el modelo comunicativo tradicional por un modelo horizontal de la comunicación en el que se busca la implicación de los usuarios en la elaboración, la propagación y el intercambio de contenidos.

Sin embargo, la construcción colaborativa del periodismo en los medios sociales en cuanto a la adaptación del lenguaje a la antes mencionada narrativa propia de este entorno ${ }^{1}$, en la mayoría de los casos, no consiste en una labor sencilla para los medios. "Las estrategias informativas puestas en marcha hasta el momento concentran esfuerzos sobre todo para garantizar la presencia de las empresas de comunicación en estos espacios” (Gomes Franco e Silva, 2014, p. 24) en detrimento del estímulo al diálogo y al debate en torno a los temas que componen la agenda.

\subsection{La importancia de Twitter y sus principales características}

Twitter, la red de miccroblogging por excelencia, posee más de 500 millones de usuarios en el mundo, habiendo registrado en septiembre de 2013 alrededor de 200 millones de usuarios activos² (Salgado \& González, 2013). Diversos estudios han hecho hincapié en la importancia de esta plataforma en el contexto informativo, subrayando su presencia destacada en las rutinas periodísticas (Lysak, et ál., 2012; Carrera, et ál., 2012).

1 El concepto de narrativa de las redes sociales o social network storytelling utilizado en este artículo es el mismo que emplea Noguera Vivo (2010) cuando se refiere a que en las redes es necesario ofrecer al público un valor añadido, huyendo de la mera duplicación de contenidos en distintas plataformas. A esta definición se añade, asimismo, el uso de un lenguaje más cercano, que rompa con la unidireccionalidad del discurso informativo tradicional.

2 Según Moreno (2013), los usuarios activos son aquellos que han hecho login en Twitter al menos una vez en los últimos 30 días. 
En España, Carrera (2011) señala que un elevado porcentaje de los periodistas prefieren Twitter a Facebook para publicar y distribuir información (incluidos los breaking news), acceder a las fuentes, identificar los temas de moda o buscar información. De ello se desprende el gran potencial periodístico de dicha red, que muy probablemente esté vinculado a sus características definitorias.

El elemento clave en cuanto al funcionamiento de Twitter tiene que ver con la extensión del texto que se publica en cada una de las entradas llamadas tweets o tuits. Cebrián Herreros (2013, p. 51) los define como los "mensajes resultantes de las intervenciones de los usuarios no solo referidos a las actualizaciones de una noticia sino a cualquier participación". Esas "pequeñas explosiones de información" (Twitter, 2013) deben tener una longitud máxima de 140 caracteres.

Un tuit puede contener hashtags -etiquetas en las que se incluye el símbolo de la almohadilla (\#)-, menciones a otros internautas mediante la inserción de los nombres de usuario (@usuario) o enlaces acortados ${ }^{3}$ que pueden enviar al visitante a otras páginas web. En cuanto a la dinámica y los términos propios de la red de microblog, Puebla Martínez y Gomes Franco e Silva (2014, p. 286) explican que:

La nomenclatura típica de Twitter engloba términos como followers (seguidores) o following (siguiendo). Los internautas pueden optar por efectuar un retweet o RT de una publicación de otro usuario para que esta sea visible en su timeline o línea del tiempo, ampliando el alcance del tuit. Las conversaciones normalmente se desarrollan a partir de una mención, que puede ser contestada a través de un reply. Si el usuario prefiere que el mensaje destinado a otro internauta no sea visible en su línea del tiempo, puede optar por enviarle un direct message (DM) o mensaje directo, garantizando así la privacidad de la conversación.

Aparte de ello, conviene mencionar la existencia de un botón específico para la interacción del usuario con el tuit a través del cual puede indicar que este es su contenido favorito. Para ello, deberá hacer clic en el ícono de una estrella que aparece de forma automática en el propio recuadro del tuit, al lado de los botones "Retuitear" y "Responder".

En los perfiles de los medios de comunicación, los tuits informativos pueden tener, por un lado, un carácter meramente referencial y divulgativo o, por otro lado, un carácter interactivo y conversacional. Según García de Torres, et ál. (2011), en el primer caso, se hace referencia a la web del medio con el fin de que el usuario la visite; en el segundo caso, se añaden elementos que estimulan el diálogo, como puede ser una pregunta al usuario solicitando su opinión sobre determinado asunto.

\section{Objetivos}

El objetivo principal de la presente investigación consiste en trazar un paralelismo entre España y Portugal mediante un análisis de las estrategias comunicativas utilizadas en Twitter por sus periódicos de referencia. Para llevar a cabo dicha comparativa, se han tenido en consideración los siguientes objetivos específicos:

3 Existen diversos sitios web que realizan de forma gratuita la reducción de las direcciones electrónicas. Estas páginas suelen ofrecer un campo específico para que el usuario introduzca la URL que desee acortar. Al presionar el botón correspondiente a la acción deseada, la web le facilita una versión resumida de la URL inicial, manteniendo la dirección de destino del hipervínculo. 
- Realizar una exploración tanto de los perfiles de los medios como de sus timelines.

- Conocer las principales características de las publicaciones de los periódicos en Twitter, destacando los elementos que componen los tuits emitidos por ellos.

- Identificar los tipos de tuits de acuerdo con el carácter (referencial o conversacional.

- Comprobar si los cibermedios analizados incorporan a su actividad en el microblogging la práctica de contestar a los usuarios mediante el uso del reply.

- Observar la existencia o no de macronavegación a través de la utilización de enlaces que envíen al internauta a otras páginas web ajenas al medio.

- Identificar los tipos de tuits con mayor éxito en cuanto al alcance y a la participación de los usuarios durante el período de análisis.

A continuación, se expone la metodología utilizada para la realización de este estudio, teniendo presentes las herramientas que se consideran viables a la hora de promover el cumplimiento de los objetivos propuestos.

\section{Metodología}

Para llevar a cabo una exploración de las páginas de Twitter de los cibermedios elegidos -El País en España y Jornal de Notícias en Portugal-y realizar un acercamiento a los tipos de tuits publicados por ellos, se han elaborado dos fichas de análisis de contenido que han sido aplicadas a los dos perfiles estudiados, del 14 al 20 de julio de 2014, semana elegida al azar. La primera ficha contempla variables asociadas a la cuenta en sí, mientras que la segunda se centra en los aspectos que se pretenden analizar en los propios tuits, tales como los tipos de enlace que contienen, la presencia de hashtags, menciones, etc.

La estructura de las plantillas está inspirada en la propuesta de Noguera Vivo (2010) para el estudio de la actividad de los medios en Facebook. En esa ocasión, el autor realizó una observación estructurada de los perfiles de 13 cibermedios españoles en dicha plataforma a lo largo del martes 1 de diciembre de 2009. Para el referido estudio exploratorio, Noguera Vivo elaboró una serie de variables distribuidas en distintos bloques temáticos, los cuales, en la presente investigación, han sido adaptados a Twitter con base en el análisis llevado a cabo por García de Torres, et ál. (2011).

Considerando la primera unidad de análisis (la cuenta del periódico en Twitter), se ha diseñado una ficha en la que se recogen los siguientes datos formales: dirección de la página de Twitter analizada (URL); nombre de usuario adoptado por el cibermedio; información básica de perfil (cómo el diario se presenta ante los usuarios); mes y año de apertura de la cuenta; total de seguidores, y presencia de retuits internos o externos. En este estudio, se considera RT interno aquel retuit realizado por el periódico de los contenidos publicados anteriormente por otras cuentas del propio cibermedio. Ej.: los retuits hechos por la cuenta de El País (@el_pais) de los tuits publicados por los usuarios@elpais_tec, @elpais_deportes o @elpais_info. A su vez, un RT externo es aquel retuit efectuado por el periódico de las publicaciones realizadas por otros usuarios no derivados de la cuenta oficial del cibermedio.

Conforman la segunda unidad de análisis los tuits emitidos por los diarios, en cuya ficha específica se recogen los datos enumerados a continuación: carácter de cada publicación (referencial o conversacional); tipología del tuit (véase tabla 1); transversalidad (presencia de enlaces externos en los tuits, o sea, que remiten a los usuarios a páginas web ajenas al medio); número de menciones, hashtags y fotografías; número de replies; cantidad de 
veces que el tuit ha sido retuiteado, y, por último, la cifra de favoritos. Los datos han sido recopilados y tratados en SPSS 19.

\section{Tabla 1. Carácter y tipología de tuits}

\begin{tabular}{|c|c|}
\hline Referenciales & Conversacionales \\
\hline Titular diferenciado sin enlace & Invita a participar: pide opinión (sin enlace) \\
\hline Titular diferenciado con enlace interno & Invita a participar: pide opinión (con enlace interno) \\
\hline Titular original sin enlace & Invita a ver la información (sin enlace) \\
\hline Titular original con enlace interno & Invita a ver la información (con enlace interno) \\
\hline Titulares de portada con enlace interno & Anuncia entrevista online e invita a participar (sin enlace) \\
\hline Anuncia entrevista online (con enlace interno) & Anuncia entrevista online e invita a participar (con enlace interno) \\
\hline Titular con enlace a Facebook & Saludo/despedida (sin enlace) \\
\hline Titular con enlace a otras redes sociales & Saludo/despedida (con enlace interno) \\
\hline Titular exclusivo de Twitter & Invita a opinar/comentar en Facebook \\
\hline- & Invita a opinar/participar en otras redes sociales \\
\hline- & Mensaje informal \\
\hline- & Solicita información/contenido (con enlace interno) \\
\hline- & Anuncia e invita a seguir cobertura (sin enlace) \\
\hline- & Anuncia e invita a seguir cobertura (con enlace interno) \\
\hline- & Anuncia oferta e invita a comprar el periódico impreso \\
\hline- & Agradece la participación \\
\hline- & Disculpas/corrección \\
\hline
\end{tabular}

Fuente: elaboración propia.

La codificación de los tuits se ha hecho de acuerdo con el contenido textual de dichas publicaciones, puesto que es en el texto donde se ubican los elementos referenciales o conversacionales analizados ${ }^{4}$. Se tienen en cuenta las imágenes ilustrativas con el propósito de identificar las distintas estrategias de comunicación en Twitter, sin analizar, no obstante, el contenido de las mismas. La clasificación de los enlaces en internos o externos ha permitido verificar la presencia o no de transversalidad en el perfil de los medios, lo que estimula una navegación no lineal y multiweb en lugar del walled garden que intenta mantener al usuario el máximo de tiempo posible en una misma página.

4 No se ha realizado una identificación temática de los tuits, debido a que este aspecto no se contempla como uno de los objetivos de la presente investigación. 
En cuanto a la tipología de los tuits, en el caso de los referenciales, se ha utilizado la nomenclatura "titular original" para indicar los titulares idénticos tanto en Twitter como en la web del medio, mientras que en el "titular diferenciado" se percata la utilización de palabras distintas, modificando la construcción del titular publicado originalmente en el cibermedio. En la tabla 1, se observan todas las tipologías de tuits, tanto referenciales como conversacionales.

\subsection{La muestra}

Han sido seleccionados para la muestra dos cibermedios informativos de "referencia dominante" (Imbert \& Vidal Beneyto, 1986) en sus países de origen: El País, con sede en Madrid (España), y Jornal de Notícias, con sede en Oporto (Portugal). Se trata de dos periódicos digitales procedentes de una cabecera impresa homónima, generalista y de alcance nacional con mayor tirada y circulación en ambos países.

El País (España) computa un promedio de tirada de 359809 ejemplares y un promedio de circulación de 292227 (en el período controlado de enero a diciembre de 2013) según la Oficina de Justificación de la Difusión (OJD). Por su parte, Jornal de Notícias (Portugal) cuenta con un promedio de tirada de 91186,67 ejemplares y con un promedio de circulación de 67503,67 (cálculo aproximado teniendo en cuenta los datos de circulación desde el primero hasta el sexto bimestre de 2013) según la Associação Portuguesa para o Controlo de Tiragem e Circulação (APCT).

Tabla 2. Datos relativos a los medios analizados

\begin{tabular}{|c|c|c|c|c|}
\hline Cabecera & Origen & URL & $\begin{array}{c}\text { Promedio } \\
\text { Tirada }\end{array}$ & $\begin{array}{l}\text { Promedio } \\
\text { Circulación }\end{array}$ \\
\hline El País & Madrid (España) & https://twitter.com/el_pais & 359809 & 292227 \\
\hline Jornal de Notícias & Oporto (Portugal) & https://twitter.com/JornalNoticias & 91186,67 & 67503,67 \\
\hline
\end{tabular}

Fuente: elaboración propia.

\section{Resultados}

Las plantillas de análisis fueron aplicadas a las páginas de los cibermedios en Twitter a partir de una observación estructurada de los perfiles analizados. El corpus de la investigación lo conforman un total de 640 mensajes emitidos, de los cuales 269 pertenecen a Jornal de Notícias y 371 a El País. El número de mensajes publicados son los comprendidos en la semana del 14 al 20 de julio de 2014.

\subsection{Información básica de perfil}

De las dos cabeceras de la muestra, el diario español fue el primero en unirse a la práctica del microblogging, en agosto de 2007, un año después de la creación de Twitter. Once meses más tarde, en julio de 2008, creó su cuenta Jornal de Notícias. 
La información básica de perfil, con la que el usuario se presenta a los demás, es más completa en El País que en Jornal de Notícias. En el perfil español se observa la información relativa al tipo de actividad que pueden encontrar los internautas en la página social del diario. Con la frase "Para informarse y conversar", el periódico hace alusión a los tipos de mensajes emitidos (referenciales y conversacionales), invitando, de este modo, no solo a leer sus tuits, sino también a participar con comentarios al resto de usuarios. Por su parte, Jornal de Notícias no incluye en su perfil ningún tipo de información adicional, lo que puede llevar a equívocos a la hora de seguir al cibermedio.

Tabla 3. Creación de perfiles, información básica y seguidores (a fecha de 20 de julio de 2014)

\begin{tabular}{|l|l|l|l|l|}
\hline \multicolumn{2}{|c|}{$\begin{array}{c}\text { Cabecera } \\
\text { El País }\end{array}$} & $\begin{array}{c}\text { Fecha de adhesión } \\
\text { a Twitter }\end{array}$ & $\begin{array}{c}\text { Número de } \\
\text { seguidores }\end{array}$ & $\begin{array}{l}\text { Las noticias globales más } \\
\text { relevantes y la última hora en } \\
\text { español, por los periodistas } \\
\text { de EL PAís. Para informarse y } \\
\text { conversar. }\end{array}$ \\
\hline Jornal de Notícias & @el_pais & Agosto de 2007 & 3257734 & \\
\hline
\end{tabular}

Fuente: elaboración propia.

Aunque el promedio de tirada y de difusión de los periódicos en papel es superior en El País, 3,94 veces más de tirada y 4,32 veces más de difusión que Jornal de Notícias - debido, quizá, a una cuestión de diferencia poblacional entre países, puesto que España tiene 4,51 veces más habitantes que Portugal ${ }^{5}-$, en el caso de los cibermedios, esta diferencia es todavía mucho más manifiesta: el diario El País posee 23,8 veces más seguidores que Jornal de Notícias.

\subsection{Frecuencia de publicación y dinamismo}

Es, sin duda, el medio español el que actualiza con mayor frecuencia su timeline con una media de 53 tuits al día frente a los 38 tuits de Jornal de Notícias.

Se ha podido observar que el volumen de publicaciones del cibermedio portugués decae los fines de semana, respetando de este modo, incluso en el ámbito digital, la rutina del trabajo dispuesta en días laborables y no laborables. En cambio, El País opta por alimentar continuamente su perfil con independencia del día de la semana en que se publique, aunque, como muestra la gráfica 1, existe una mínima disminución en el fin de semana ${ }^{6}$.

5 En 2013, había 47265321 habitantes en España y 10459806 en Portugal, según datos del Instituto Nacional de Estadística (INE).

6 Sería necesario ampliar el periodo muestral para registrar y comprobar dicho resultado. 


\section{Gráfica 1. Total de tuits al día}

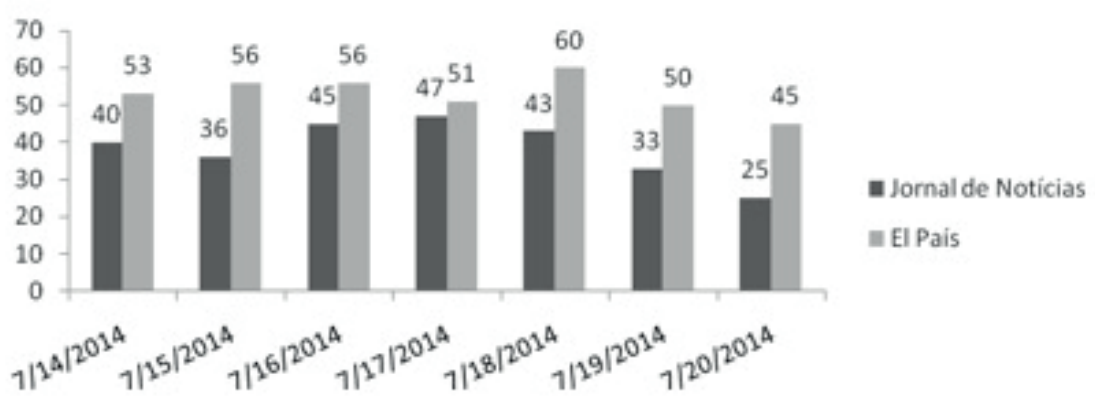

Fuente: elaboración propia.

Una de las grandes diferencias que presentan ambos cibermedios es la utilización de retuits tanto internos como externos. En el caso de Jornal de Notícias, no se ha encontrado ningún tipo de retuit realizado por el medio. En cambio, El País presenta todos los días retuits internos, con una media al día de 13,14 RT. Es necesario precisar, como se comentó anteriormente, que El País cuenta con numerosas cuentas específicas del propio cibermedio especializadas en las secciones del diario, entre otras como @elpais_deportes, @elpais_cultura, @elpais_economia... ${ }^{7}$ A su vez, el diario español también realiza diversos retweets externos (5,42 RT externos al día), en la mayoría de las ocasiones procedentes de las cuentas de periodistas relacionados con el medio. Este hecho da lugar a un mayor nivel de dinamismo en cuanto a la diversificación de usuarios presentes en la línea del tiempo del diario español a la vez que este intenta fidelizar a los internautas republicando contenidos emitidos por fuentes vinculadas al propio cibermedio.

\subsection{Análisis de los tuits}

En cuanto al carácter de las publicaciones de los cibermedios en Twitter, se observa que los mensajes referenciales tienen mucha más presencia que los conversacionales. De la totalidad del corpus analizado, solamente un $5 \%$ de los mensajes han sido clasificados de acuerdo con la tipología conversacional (ver gráfica 2).

7 A día 20 de julio de 2014 se han contabilizado 36 cuentas diferentes que pertenecen a El País. 


\section{Gráficas 2, 3 y 4. Carácter de los mensajes en Twitter}
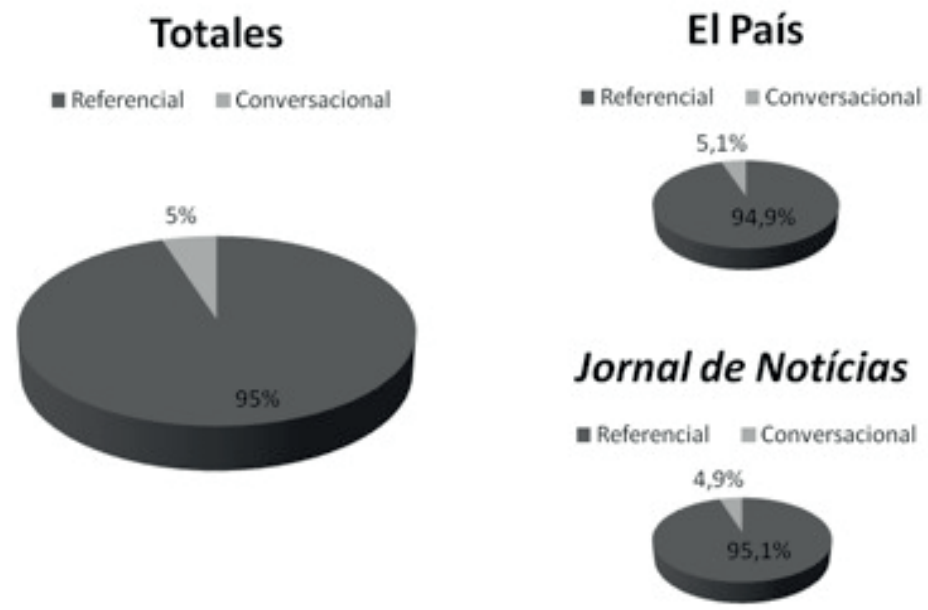

Fuente: elaboración propia.

Los tipos de mensajes más frecuentes en Twitter corresponden a las siguientes tipologías pertenecientes a la categoría referencial: (1) "Titular diferenciado con enlace interno", con un total de 370 tuits (60,8\% del total de tuits), y (2) "Titular original con enlace interno", con 227 tuits (37,3\% del total de tuits). Cabe destacar que el (1) es el más utilizado por El País, con 331 tuits (94\% de sus tuits pertenecen a esta categoría), y el (2) por Jornal de Notícias, con 207 tuits (80,8\% sobre su muestra). La tipología (2) consiste, por tanto, en una mera repetición del contenido publicado en la web del medio, mientras que la (1) deriva de una reelaboración del titular original con el fin de ofrecer al usuario de Twitter un contenido diferenciado.

Respecto a las tipologías de carácter conversacional, las más utilizadas son: (1) "Invita a ver la información con enlace interno", con 14 tuits (2,3\% del total de tuits), seguida de (2) "Anuncia entrevista online e invita a participar (con enlace interno)", con cinco tuits ( $0,8 \%$ del total de tuits). En este caso es El País el que utiliza más veces la primera opción (12 veces de las 14) y Jornal de Notícias se decanta más por anunciar e invitar a seguir la cobertura (con enlace interno) y por realizar un saludo o despedida (sin enlace), con cuatro veces cada opción.

Tabla 4. Carácter de los tuits

\begin{tabular}{|l|c|c|c|}
\hline Carácter referencial & Jornal de Notícias & El País & TOTAL \\
\hline Titular diferenciado con enlace interno & 39 & 331 & 20 \\
\hline Titular original con enlace interno & 207 & 1 & 227 \\
\hline Titulares de portada con enlace interno & 0 & 0 & 3 \\
\hline Titular con enlace a otras redes sociales & 3 & 2 \\
\hline
\end{tabular}




\begin{tabular}{|c|c|c|c|}
\hline Carácter referencial & Jornal de Notícias & El País & TOTAL \\
\hline Titular exclusivo de Twitter & 7 & 0 & 7 \\
\hline SUBTOTAL & 256 & 352 & 608 \\
\hline \multicolumn{4}{|l|}{ Carácter conversacional } \\
\hline Anuncia e invita a seguir la cobertura (con enlace interno) & 4 & 0 & 4 \\
\hline Invita a ver la información (sin enlace) & 1 & 0 & 1 \\
\hline Invita a ver la información (con enlace interno) & 2 & 12 & 14 \\
\hline $\begin{array}{l}\text { Anuncia entrevista online e invita a participar (con enlace } \\
\text { interno) }\end{array}$ & 1 & 4 & 5 \\
\hline Invita a opinar/participar en otras redes sociales & 1 & 0 & 1 \\
\hline Saludo/despedida (sin enlace) & 4 & 0 & 4 \\
\hline Solicita información/contenido (con enlace interno) & 0 & 3 & 3 \\
\hline SUBTOTAL & 13 & 19 & 32 \\
\hline TOTAL & 269 & 371 & 640 \\
\hline
\end{tabular}

Fuente: elaboración propia.

La inclusión de enlaces externos en los mensajes no ha sido parte de la estrategia de ninguno de los dos medios. En todo el corpus analizado no se ha encontrado ningún caso de macronavegación propuesto por parte de alguno de los diarios analizados.

Otros elementos importantes para conocer las estrategias comunicativas de cada cibermedio son las menciones a otros usuarios, los hashtags y el uso de imágenes. En el análisis realizado, la diferencia entre ambos cibermedios es ingente. El diario portugués apenas utiliza las posibilidades otorgadas por Twitter para potenciar la visibilidad y el alcance de cada tuit, así como para generar más interés por determinados contenidos. Por su parte, El País hace mucho más uso de estos elementos, pero sin una regla establecida. Es decir, en ocasiones utiliza la mención a un usuario o el hashtag y en otras no. Por ejemplo:

El País, 15/07/2014: Entrevista a Pedro Sánchez, líder del PSOE: "Haré posible un giro a la izquierda que permita ganar elecciones" http://cort.as/DmsZ

El País, 15/07/2014: Jáuregui (@PSOE) justifica el no a Juncker por el mandato de Pedro Sánchez @sanchezcastejon http://ow.ly/zamBD pic.twitter.com/nwalmLVSVu

El País, 16/07/2014: Israel ordena a 100.000 palestinos a que evacuen sus viviendas, México libera a 458 menores esclavizados, en \#Portada http://cort.as/EB_G

El País, 14/07/2014: Alemania vuelve a lo más alto y los socialistas españoles eligen a Pedro Sánchez como nuevo líder http://ow.ly/z6PaG Portada de EL PAís

En los ejemplos mencionados, se observa el uso de la sigla del Partido Socialista Obrero Español convertida en mención en algunos casos, pero no en todos. Asimismo, se percata el uso del término "Portada" asociado en 
ocasiones al símbolo de la almohadilla, lo que permite al usuario acceder fácilmente a todos los tuits relacionados con este hashtag en concreto. El hecho de no usarlo siempre, excluye aquellos tuits que no incluyan la referida etiqueta y que permitirían al internauta tener un acceso directo a la portada del periódico cuando buscara en Twitter el hashtag \#Portada.

Como se ha comentado anteriormente, Jornal de Notícias no realiza menciones en sus tuits. No se ha encontrado ningún ejemplo en toda su muestra. En cambio, El País sí utiliza este elemento, pero de una manera moderada. Como se puede ver en la tabla 5, aparecen más menciones en los tuits de carácter referencial, siendo el más habitual dentro de la tipología "Titular diferenciado con enlace interno", con 69 tuits con una mención, 15 con dos y dos tuis, dispuestos a continuación, con hasta tres menciones:

El País, 17/07/2014: El partido @ahorapodemos, liderado por @Pablo_Iglesias_, urge a sus bases a actuar antes de que el @PSOE se “recupere” http://cort.as/EBsn

El País, 20/07/2014: \#EncuestaMetroscopia: Intención directa de voto en Cataluña: $1^{\circ} @ E s q u e r r a \_E R C, 2^{\circ} @ a h o-$ rapodemos, $3^{\circ} @$ CiU 40 $\rightarrow$ http://cort.as/EQs5

En el caso de los tuis de carácter conversacional, no destaca de sobremanera ninguna de las tipologías establecidas.

\section{Tabla 5. Menciones en los tuits}

\begin{tabular}{|c|c|c|c|c|c|}
\hline El País & Sin mención & Una mención & Dos menciones & Tres menciones & TOTAL \\
\hline \multicolumn{6}{|l|}{ Carácter referencial } \\
\hline $\begin{array}{l}\text { Titular diferenciado con enlace } \\
\text { interno }\end{array}$ & 245 & 69 & 15 & 2 & 331 \\
\hline Titular original con enlace interno & 15 & 5 & 0 & 0 & 20 \\
\hline $\begin{array}{l}\text { Titulares de portada con enlace } \\
\text { interno }\end{array}$ & 1 & 0 & 0 & 0 & 1 \\
\hline TOTAL & $261(74,1 \%)$ & $74(21 \%)$ & $15(4,3 \%)$ & $2(0,6 \%)$ & $352(100 \%)$ \\
\hline \multicolumn{6}{|l|}{ Carácter conversacional } \\
\hline $\begin{array}{l}\text { Invita a ver la información (con enlace } \\
\text { interno) }\end{array}$ & 11 & 1 & 0 & 0 & 12 \\
\hline $\begin{array}{l}\text { Anuncia entrevista online e invita a } \\
\text { participar (con enlace interno) }\end{array}$ & 1 & 2 & 1 & 0 & 4 \\
\hline $\begin{array}{l}\text { Solicita información/contenido (con } \\
\text { enlace interno) }\end{array}$ & 2 & 1 & 0 & 0 & 3 \\
\hline TOTAL & $14(73,7 \%)$ & $4(21 \%)$ & $1(5,3 \%)$ & $0(0 \%)$ & $19(100 \%)$ \\
\hline
\end{tabular}

Fuente: elaboración propia. 
Siguiendo con los elementos analizados, tal y como se ha explicado con anterioridad, los hashtags permiten etiquetar términos para facilitar su seguimiento. El uso de etiquetas por parte de los cibermedios es bastante escaso. Ambos periódicos publican la mayoría de los tuits sin ningún término etiquetado (92,5\% en el caso de El País y $94,1 \%$ en Jornal de Notícias). El resto de resultados es poco significativo. Sin embargo, si se tiene en cuenta que mediante el uso de los hashtags un tema concreto puede convertirse en Trending Topic, sí resulta significativo el hecho de que los medios analizados obvien dicho elemento.

\section{Gráficas 5 y 6. Porcentaje de hashtags por cibermedio}

\section{El País}

- Sinhashtag = Unhashtag = Dos hashtags

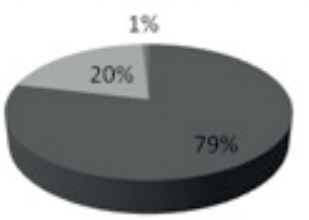

\section{Jornal de Notícias}

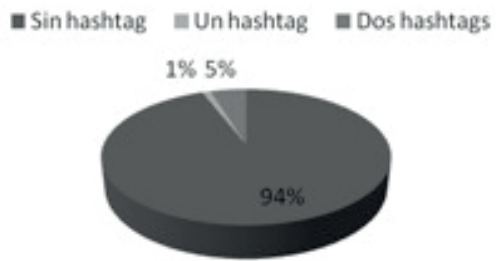

Fuente: elaboración propia.

Tabla 6. Hashtags en los tuits

\begin{tabular}{|l|c|c|c|c|}
\hline El País & Sin hashtag & Un hashtag & Dos hashtags & TOTAL \\
\hline Carácter referencial & $325(92,4 \%)$ & $23(6,5 \%)$ & $4(1,1 \%)$ & $352(100 \%)$ \\
\hline Carácter conversacional & $18(94,7 \%)$ & $1(5,3 \%)$ & $0(0 \%)$ & $19(100 \%)$ \\
\hline TOTAL & $343(92,5 \%)$ & $24(6,5 \%)$ & $4(1 \%)$ & $371(100 \%)$ \\
\hline Jornal de Notícias & Sin hashtag & Un hashtag & Dos hashtags & TOTAL \\
\hline Carácter referencial & $246(96,1 \%)$ & $2(0,8 \%)$ & $8(3,1 \%)$ & $256(100 \%)$ \\
\hline Carácter conversacional & $7(53,8 \%)$ & $1(7,7 \%)$ & $5(38,5 \%)$ & $13(100 \%)$ \\
\hline TOTAL & $253(94,1 \%)$ & $3(1,1 \%)$ & $13(4,8 \%)$ & $269(100 \%)$ \\
\hline
\end{tabular}

Fuente: elaboración propia.

Por último, se presenta la utilización de fotografías por parte de los cibermedios. El País realiza un uso mucho más destacado de las imágenes fijas que Jornal de Notícias. Más de la mitad de los tuits de El País incluyen al menos una fotografía (63,4\% con una imagen). Conviene señalar, además, que en siete tuits de carácter referencial (1,9\%) han sido incluidas hasta cuatro fotografías. Por su parte, la mayoría de los tuits de carácter conversacional (84,2\%) contienen una imagen. 
En cambio, el 95,2\% de los tuits publicados por Jornal de Notícias, lo que corresponde a 256 mensajes, no presenta ninguna fotografía. Y tan solo $13(4,8 \%)$ contienen una imagen. No se ha encontrado ningún tuit con más de dos fotografías.

Gráficas 7 y 8 . Porcentaje de fotografías en los tuits
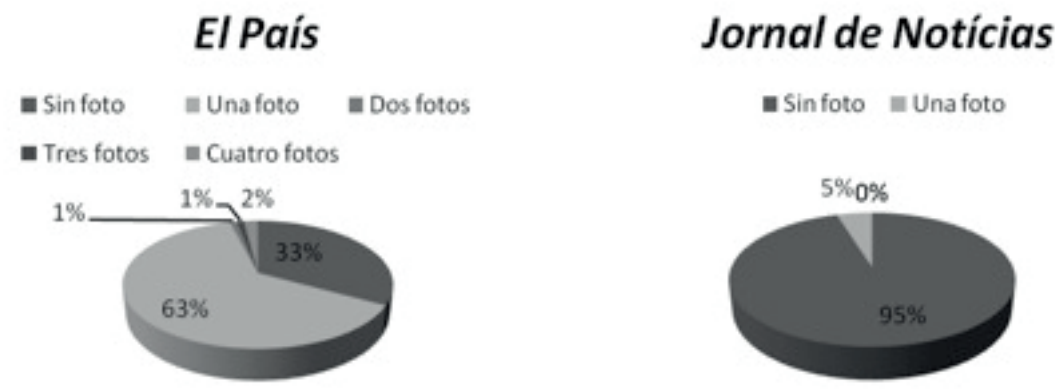

Fuente: elaboración propia.

Tabla 7. Fotografías en los tuits

\begin{tabular}{|c|c|c|c|c|c|c|}
\hline El País & Sin foto & Una foto & Dos fotos & Tres fotos & Cuatro fotos & TOTAL \\
\hline Carácter referencial & $118(33,5 \%)$ & $219(62,2 \%)$ & $3(0,9 \%)$ & $5(1,4 \%)$ & $7(2 \%)$ & $352(100 \%)$ \\
\hline $\begin{array}{l}\text { Carácter } \\
\text { conversacional }\end{array}$ & $3(15,8 \%)$ & $16(84,2 \%)$ & $0(0 \%)$ & $0(0 \%)$ & $0(0 \%)$ & $19(100 \%)$ \\
\hline TOTAL & $121(32,6 \%)$ & $235(63,4 \%)$ & $3(0,8 \%)$ & $5(1,3 \%)$ & $7(1,9 \%)$ & $371(100 \%)$ \\
\hline Jornal de Noticias & Sin foto & Una foto & Dos fotos & Tres fotos & Cuatro fotos & TOTAL \\
\hline Carácter referencial & $249(97,2 \%)$ & $7(2,8 \%)$ & $0(0 \%)$ & $0(0 \%)$ & $0(0 \%)$ & $256(100 \%)$ \\
\hline $\begin{array}{l}\text { Carácter } \\
\text { conversacional }\end{array}$ & $7(53,8 \%)$ & $6(46,2 \%)$ & $0(0 \%)$ & $0(0 \%)$ & $0(0 \%)$ & $13(100 \%)$ \\
\hline TOTAL & $256(95,2 \%)$ & $13(4,8 \%)$ & $0(0 \%)$ & $0(0 \%)$ & $0(0 \%)$ & 269 (100\%) \\
\hline
\end{tabular}

Fuente: elaboración propia.

Igualmente, se han analizado los mensajes que incluyen más de un elemento. Tan solo siete tuits de El País (1,9\% de sus mensajes) cuentan con los tres elementos mencionados. La composición que más se reproduce por parte de este medio es la mención junto al hashtag (en 65 ocasiones; 17,6\% de sus tuits). A continuación, se presentan algunos tuits a modo de ejemplo:

El País, 19/07/2014: \#CongresoPSC @sanchezcastejon dice que nunca pactará con la derecha http://cort.as/ ElzN No hay fecha de primarias pic.twitter.com/TolJFohA8s 


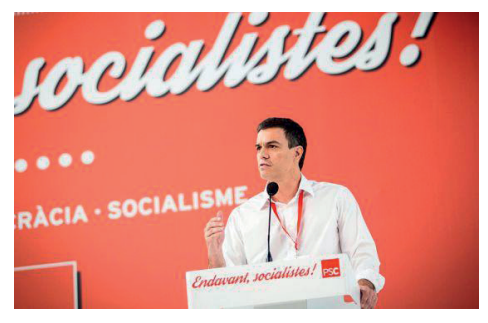

El País, 20/07/2014: Crónica: A pesar del alto el fuego, las explosiones siguen en \#Gaza. Por @gomez_jn http:// cort.as/EQqL pic.twitter.com/wMDfq860lf

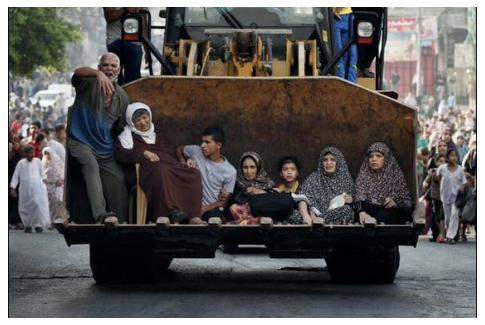

En el caso de Jornal de Notícias, se ha podido observar un único tuit que congrega hashtag y fotografía:

Jornal de Notícias, 19/07/2014: Estivemos à conversa com André Tentugal, dos We Trust. Não perca a entrevista no JN! \#jnmaresvivas \#maresvivas pic.twitter.com/zaMgAdKLqj

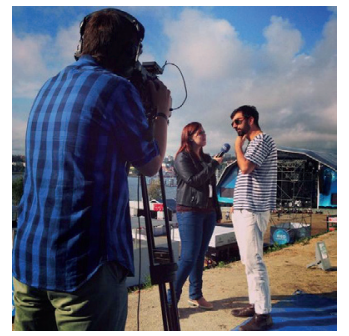

Tabla 8. Número de tuits con diferentes elementos

\begin{tabular}{|l|c|c|c|}
\hline SUMAS & El País (371) & Jornal de Noticias (269) & TOTAL (640) \\
\hline @ + \# + Foto & $7(1,9 \%)$ & $0(0 \%)$ & $7(1,1 \%)$ \\
\hline @ +\# & $9(2,4 \%)$ & $0(0 \%)$ & $9(1,4 \%)$ \\
\hline @ + Foto & $65(17,6 \%)$ & $0(0 \%)$ & $65(10,2 \%)$ \\
\hline \#+ Foto & $19(5,1 \%)$ & $1(0,4 \%)$ & $20(3,1 \%)$ \\
\hline
\end{tabular}

Fuente: elaboración propia. 
En definitiva, los datos apuntan el laxo uso que ambos cibermedios tienen de menciones y hashtags. El País utiliza en mayor medida las fotografías con una media de 0,77 por tuit. Por su parte, los datos marcan a Jornal de Notícias como el medio que más usa hashtags $(0,11)$ y destacan la nula utilización de menciones por parte de este diario.

Tabla 9. Medias de menciones, hashtags y fotografías

\begin{tabular}{|l|c|c|c|}
\hline MEDIAS & Menciones & Hashtags & Fotografías \\
\hline El País & 0,31 & 0,09 & 0,77 \\
\hline Jornal de Notícias & 0 & 0,11 & 0,05 \\
\hline
\end{tabular}

Fuente: elaboración propia.

\subsection{Análisis de la interactividad y alcance de los tuits}

Respecto a la interactividad, se ha comprobado que la retroalimentación pública por parte de ambos diarios digitales es nula. No se ha encontrado ningún reply en sus timelines. Con ello, se detecta que los referidos cibermedios no contemplan en su estrategia comunicativa en Twitter la respuesta directa al usuario.

Respecto a los retuits realizados por los internautas, la diferencia entre ellos es muy elevada. Frente a la media de 7598 retuits al día o la media de 142,8 retuits por tuit de El País, se encuentra la exigua media de 63 retuits al día o la media de 1,65 retuits por tuit de Jornal de Notícias.

Tabla 10. Media de retuits por cibermedio

\begin{tabular}{|l|c|c|}
\hline MEDIAS & Retuits/dia & Retuits / tuit \\
\hline El País & 7598 & 142,8 \\
\hline Jornal de Notícias & 63 & 1,65 \\
\hline
\end{tabular}

Fuente: elaboración propia.

Aunque la referencia no es exacta, debido a que no solo los seguidores de un usuario pueden retuitear un tuit publicado por este, es oportuno reseñar que si se obtiene el porcentaje de retuits que correspondería a cada seguidor, los datos arrojados son muy similares. Es decir, que pese a la gran diferencia de seguidores -3257734 de El País frente a los 136626 de Jornal de Notícias-, el porcentaje de retuits es de 0,23\% y de 0,05\% respectivamente. Por tanto, la diferencia entre ambos respecto a los retuits en un contexto simulado no sería tan elevada.

En el caso de El País, los tuits con más retuits pertenecen a la tipología referencial "Titular diferenciado con enlace interno". Respecto a los de carácter conversacional, tan solo uno supera la centena de retuits (con 118), el cual ha sido clasificado como "Invita a ver la información con enlace interno". En Jornal de Notícias, los tuits con más retuits son también de carácter referencial y de la misma tipología que El País. En cuanto a los de carácter 
conversacional, igualmente es la tipología que "Invita a ver la información con enlace interno" la que más retuits recibe. A continuación, se presentan los tuits con más retuits de ambos cibermedios.

El País, 16/07/2014, con 2307 retuits: Un bombardeo israelí sobre la playa de Gaza mata a 4 niños

http://internacional.elpais.com/internacional/2014/07/16/actualidad/1405492286_551846.html...

Testigo: "Los niños estaban jugando"

pic.twitter.com/n5udoqjm3S

El País, 19/07/2014, con 1576 retuits: Los muertos en Gaza superan ya los 330, de ellos 72 eran niños o mujeres menores de 18 años http://cort.as/EKrw pic.twitter.com/W2ISychUge

Jornal de Notícias, 17/07/2014, con 19 retuits: Tanques israelitas voltam a bombardear hospital em Gaza http:// dlvr.it/6M2GR5 Leer http://www.JN.pt

Jornal de Notícias, 17/07/2014, con 18 retuits: ÚLTIMA HORA: Avião malaio abatido na Ucrânia com 295 pessoas a bordo http://goo.gl/Vin6bf

Analizando los favoritos marcados por los usuarios, la diferencia entre los medios es también muy elevada. Frente a la media de 3023 favoritos al día o la media de 56,7 favoritos por tuit de El País, se encuentra la nimia media de 47 favoritos al día o la media de 1,3 favoritos por tuit de Jornal de Notícias.

Tabla 11. Media de favoritos por cibermedio

\begin{tabular}{|l|c|c|}
\hline MEDIAS & Favoritos/dia & Favoritos/tuit \\
\hline El País & 3023 & 56,7 \\
\hline Jornal de Notícias & 47 & 1,3 \\
\hline
\end{tabular}

Fuente: elaboración propia.

Al igual que ocurría con los retuits, es pertinente referir que si se obtiene el porcentaje de favoritos que correspondería a cada seguidor, los datos son muy parejos. El porcentaje de favoritos en El País es de 0,09\% (sobre 3257734 seguidores) y de $0,05 \%$ en Jornal de Notícias (sobre 136626 followers). La diferencia entre ambos diarios respecto a los favoritos es casi imperceptible siempre y cuando se tenga en cuenta que, en este caso, se considera que los favoritos han sido señalados solamente por los seguidores del medio.

Los tuits de El País marcados con más favoritos son de carácter referencial y pertenecen a la tipología "Titular diferenciado con enlace interno". Respecto a los de carácter conversacional, son los mensajes clasificados de acuerdo con la tipología "Invita a ver la información con enlace interno" los que tienen más favoritos. En Jornal de Notícias, los tuits con más favoritos son también de carácter referencial y de la misma tipología que El País. En cuanto a los de carácter conversacional, destacan tipologías de "Saludo/despedida sin enlace" y "Anuncia entrevista online e invita a participar con enlace interno" como las que más favoritos reciben. Por último, se muestran los tuits con más favoritos de ambos cibermedios. 
El País, 18/07/2014, con 479 favoritos: Entrevista a Joaquín Sabina: "Con un libro entre manos, sabes que no estás solo" http://cultura.elpais.com/cultura/2014/07/17/actualidad/1405628736_414881.html ... pic.twitter. com/b0JZkbr51p

El País, 19/07/2014, con 436 favoritos: La película secreta de Woody Allen http://ow.ly/zkXJ2 Un sátira de la era de Nixon que fue vetado, aparece online pic.twitter.com/ZfKVpzU0r1

Jornal de Notícias, 14/07/2014, con 20 favoritos: VÍDEO: Rui Reininho abandona "The Voice Portugal" em direto http://goo.gl/0qjdC6 pic.twitter.com/FcT6S3LxxF

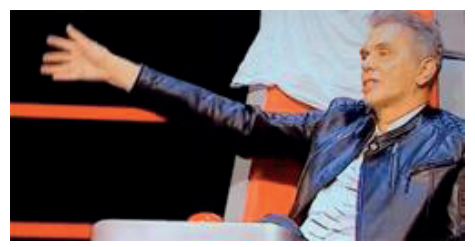

Jornal de Notícias, 15/07/2014, con 14 favoritos: Canoístas portugueses, que se sagraram campeões da Europa, pedem boleia para casa http://goo.gl/MDjTmA pic.twitter.com/0aVJ4eASpo

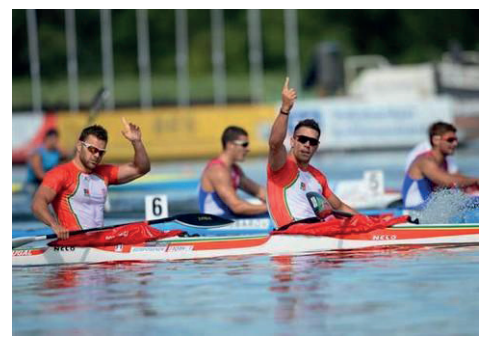

\section{Conclusiones}

El análisis de los perfiles de Twitter de los cibermedios seleccionados ha permitido realizar un acercamiento a las principales estrategias comunicativas de ambos periódicos en la red de microblogging y destacar las tácticas empleadas por ellos a la hora de componer sus respectivas líneas del tiempo. El uso mayoritariamente referencial de dicha plataforma 2.0 por parte de los periódicos evidencia la escasez de diálogo y debate, actividades propias del entorno digital interactivo, así como la infrautilización del potencial conversacional de Twitter.

En este sentido, se observa un intento aún primario de adaptar sus mensajes a la narrativa de las redes sociales con el uso de un lenguaje más cercano en algunas tipologías de tuits conversacionales, sobre todo cuando el objetivo del diario es motivar a que los internautas visualicen un contenido concreto. Sin embargo, el predominio de la referencialidad del discurso en los timelines da lugar a una clara labor de divulgación del propio cibermedio en detrimento de la conversación. La utilización de enlaces con el único propósito de redirigir al usuario a la página web del periódico ratifica dicha estrategia.

En esta línea se encuentra la utilización del retuit como un recurso alternativo para reforzar tanto el referido walled garden como la imagen de marca del diario en Internet. Los retuits internos y externos, detectados solo 
en la cuenta de El País, descartan la transversalidad y walled gardens, reduciendo el perímetro de navegación del usuario únicamente al perfil de Twitter y a la web del periódico. De este modo, la presencia reiterada del medio y su marca en los tuits y retuits dispuestos en su línea del tiempo corrobora el desarrollo del e-branding a la vez que limita la oferta de contenidos que procedan de otras fuentes, los cuales podrían comprobar y complementar la información divulgada por el cibermedio.

No obstante, la estrategia empleada en torno a la micronavegación, haciendo constante referencia al propio periódico, a sus secciones e incluso a sus periodistas, apenas contempla tácticas que promuevan la propagación de la actividad del diario en otros medios sociales. La tipología referencial, "titular con enlace a otras redes sociales", y la conversacional, "invita a opinar/participar en otras redes sociales", han sido computadas escasas veces durante el período de análisis, habiendo sido empleadas tan solo por el Jornal de Notícias.

Es reseñable el hecho de que no se haya detectado ningún reply por parte de los cibermedios, demostrando la ausencia absoluta de estrategias vinculadas a la respuesta directa y pública al internauta por parte de los periódicos. Una alternativa para buscar la implicación de la audiencia y otorgarle visibilidad en el timeline podría ser el empleo de mensajes que soliciten directamente la participación y colaboración de los usuarios, respondiéndoles a través de los replies o incluso retuiteando algunas de sus aportaciones como una deferencia hacia ellos.

Conviene destacar la necesidad de establecer criterios que definan la utilización de menciones y hashtags en los tuits. Así como los medios de comunicación suelen disponer de un manual de estilo para sus versiones impresa y online, a raíz de la realización del presente estudio, queda patente la necesidad de que estas empresas desarrollen un manual específico para el uso de dichos elementos. Para ello, es imprescindible conocer la importancia de las menciones y de las etiquetas a la hora de ampliar la visibilidad y el alcance de una publicación. Es importante señalar, asimismo, el gran potencial de estos recursos para generar diálogo.

Por tanto, se ha podido observar una considerable disparidad entre los medios respecto al uso de menciones, hashtags y también de fotografías. La ausencia de menciones en el perfil de Jornal de Notícias y la escasez de imágenes que ilustren los tuits publicados por este periódico son sin duda notables. El País, a su vez, construye su timeline de Twitter con un volumen de ilustraciones equiparable a redes de carácter más visual, como Facebook o Pinterest. La elaboración de un manual, tal y como se ha sugerido, debe tener en cuenta las particularidades de cada plataforma digital con el fin de atribuir la debida importancia a los recursos citados.

Para conocer las características de los contenidos que despiertan el interés de la audiencia, aparte del recuento de favoritos y retuits recibidos por cada mensaje, que se ha llevado a cabo en esta ocasión, es aconsejable realizar una identificación temática de los tuits. Dicho procedimiento asociado a un análisis prolongado del uso periodístico de los medios sociales, en especial de la red de microblog, puede redundar en el hallazgo de estrategias comunicativas que confluyan la demanda del público y los intereses de los medios de comunicación.

\section{Referencias}

1. Alonso, J. (2010). Cibermedios: conceptualización y tipologías. En Cabrera González, M. A. (coord.), Evolución tecnológica y cibermedios (pp. 21-38). Zamora, España: Comunicación Social Ediciones y Publicaciones. 
2. Alonso, J. \& Martínez, L. (2003). Medios interactivos: caracterización y Contenidos. En Díaz Noci, J. y Salaverría, R. (coords.), Manual de redacción ciberperiodística (pp. 261-305). Barcelona, España: Ariel.

3. Associação Portuguesa para o Controlo de Tiragem e Circulação (APCT) (2013). Informe sobre la tirada y la circulación de la prensa portuguesa. Recuperado el 16 de febrero de 2013, de http://www.apct.pt/

4. Baviera, T. (2012). La opinión publicada en los blogs. Análisis del tratamiento de temas de actualidad (política, economía y tecnología) en la blogosfera de España, Francia y Estados Unidos. Tesis Doctoral. Universidad de Valencia, Valencia, España.

5. Cabrera, M. A. (coord.) (2010). Evolución tecnológica y cibermedios. Zamora, España: Comunicación Social Ediciones y Publicaciones.

6. Campos, F. (2008). Las redes sociales trastocan los modelos de los medios de comunicación tradicionales. Revista Latina de Comunicación Social, 63, 287-293. Recuperado el 28 de septiembre de 2013, de http:// www.revistalatinacs.org/_2008/23_34_Santiago/Francisco_Campos.html

7. Carrera, P. (2011). Join the Conversation: How Spanish Journalists are Using Twitter. IAMCR 2011 Conference. Recuperado el 13 de octubre de 2013, de http://www. pilarcarrera.es/imgs/jointheconversation.pdf

8. Carrera, P.; Saiz de Baranda, C.; Herrero, E. \& Limón, N. (2012). Journalism and Social Media: How Spanish Journalists Are Using Twitter. Estudios sobre el mensaje periodístico, 18, (1), 31-53.

9. Castells, M. (2009). Comunicación y poder. Madrid, España: Alianza.

10. Castells, M. (2008). La sociedad red. Madrid, España: Alianza.

11. Cebrián, M. (2013). El periodismo entre la convergencia e interconexiones de las redes sociales. En Flores Vivar, J. M. (coord.), Contenidos y servicios periodísticos en las redes sociales (pp. 29-58). Madrid, España: Fragua.

12. Cebrián, M. (2008). La web 2.0 como red social de comunicación e información. Estudios sobre el Mensaje Periodístico, 14, 345-361.

13. Flores, J. M. (coord.) (2013). Contenidos y servicios periodísticos en las redes sociales. Madrid, España: Fragua.

14. Font, A. (2003). Las tensiones en el desarrollo de la Sociedad de la Información. Cuadernos/Sociedad de la Información, 2. Recuperado el 21 de noviembre de 2013, de http://fundacionorange.es/documentos/ analisis/cuadernos/2tensiones.pdf

15. García de Torres, Yezers'ka, L.; Rost, A.; Calderón, M.; Edo, C.; Rojano, M.; Said, E.; Jerónimo, P.; Arcila, C.; Serrano, A.; Badillo, J. \& Corredoira, L. (2011). Uso de Twitter y Facebook por los medios iberoamericanos. El profesional de la información, 6, (20), 611-620.

16. García Galindo, J. A. (2009). La Sociedad de la Información (SI). Su historia a través de TELOS, en TELOS, 81. Recuperado el 22 de abril de 2013, de http://telos.fundaciontelefonica.com/DYC/TELOS/ NMEROSANTERIORES/Nmeros8097/DYC/TELOSonline/SOBRETELOS/Nmerosanteriores/Nmero81/ seccion $=1270 \&$ idioma $=$ es_ES.do

17. Gomes Franco e Silva, F. (2014). El uso periodístico de las redes sociales: análisis comparativo entre Brasil y España. aDResearch ESIC, 9, 22-43. 
18. IAB Spain (2009). El Libro Blanco de IAB. La comunicación en Medios Sociales, 8. Recuperado el 9 de noviembre de 2013 de http://www.iabspain.net/wpcontent/uploads/downloads/2012/02/8_LB_ Comunicacion_Medios_Sociales.pdf

19. Imbert, G. \& Vidal Beneyto, J. (1986). El País o la referencia dominante. Barcelona, España: Mitre.

20. Lysak, S.; Cremedas, M. \& Wolf, J. (2012). Facebook and Twitter in the Newsroom: How and Why Local Television News is Getting Social with Viewers? Electronic News, 6, (4), 187- 207.

21. Mallabiabarrena, I. \& Meso Ayerdi, K. (2011). Uso de las redes sociales en las televisiones autonómicas. Análisis del caso vasco EITB. En Verón Lassa, J. J. y Sabés Turmo, F. (coords.), La investigación en periodismo digital. Algunos trabajos desde el ámbito universitario (pp. 140-149),. Zaragoza, España: Asociación de Periodistas de Aragón. Recuperado el 12 de diciembre de 2013, de http://duodecimo.congresoperiodismo. com/pdf/Libro\%20electronico\%202011.pdf

22. Moreno, M. (2013). Twitter tiene 218 millones de usuarios activos al mes y envía 500 millones de tuits al día. TreceBits: redes sociales y periodismo 2.0. Recuperado el 15 de febrero de 2014, de http://www. trecebits.com/2013/10/04/twitter-tiene-218-millones-de-usuarios-activos-al-mes-y-envia-500-millonesde-tuits-al-dia/

23. Noguera Vivo, J. M. (2010). Redes sociales como paradigma periodístico. Medios españoles en Facebook. Revista Latina de Comunicación Social, 65. Recuperado el 26 de marzo de 2014, de http://www. revistalatinacs.org/10/art/891_UCAM/13_JM_Noguera.html

24. Oficina de Justificación de la Difusión (OJD) (2013). Informe sobre la tirada y la circulación de la prensa española. Recuperado el 16 de febrero de 2013, de http://www.introl.es/

25. Pisani, F. (2002). ¿Y ahora qué?, Prólogo. En Islas, O.; Gutiérrez, F.; Albarrán de Alba, G.; Camarena, S. y Fuentes Berain, R. (coords.), Explorando el ciberperiodismo iberoamericano. México: CESA.

26. Puebla, B. y Gomes, F. (2014). Twitter como herramienta de lanzamiento de las series de ficción españolas: el estreno de Velvet (Antena 3) y B\&b (Telecinco). En Liberal Ormaechea, S. y Fernández Perea, P. (coords.), Últimos estudios sobre Publicidad: de 'Las Meninas' a los tuits (pp. 283-300). Madrid, España: Fragua.

27. Rojo, P. A. (2010). El medio ubicuo: tecnologías para la distribución Multiplataforma. En Cabrera González, M. A. (coord.), Evolución tecnológica y cibermedios (pp. 39-54). Zamora, España: Comunicación Social Ediciones y Publicaciones.

28. Salaverría, R. (coord.) (2005). Cibermedios: El impacto de internet en los medios de comunicación en España. Sevilla, España: Comunicación Social Ediciones y Publicaciones.

29. Salgado Santamaría, C. y González Conde, J. (2013). Las redes sociales como plataformas de medios y servicios. En Flores Vivar, J. M. (coord.), Contenidos y servicios periodísticos en las redes sociales (pp. 59-77). Madrid, España: Fragua.

30. Twitter (2013). La forma más simple y más rápida para estar cerca de lo que te interesa, en Acerca de Twitter. Recuperado el 12 de marzo de 2013, de https://twitter.com/about 